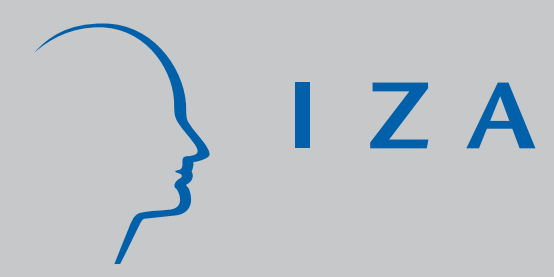

IZA DP No. 1404

The Political Economy of J ob Protection and Income Redistribution

Bruno Amable

Donatella Gatti

November 2004 


\title{
The Political Economy of Job Protection and Income Redistribution
}

\author{
Bruno Amable \\ University of Paris $X$, Nanterre \\ and CEPREMAP \\ Donatella Gatti \\ University Lumière Lyon 2, \\ CEPREMAP and IZA Bonn
}

\section{Discussion Paper No. 1404 \\ November 2004}

\author{
IZA \\ P.O. Box 7240 \\ 53072 Bonn \\ Germany \\ Phone: +49-228-3894-0 \\ Fax: +49-228-3894-180 \\ Email: iza@iza.org
}

Any opinions expressed here are those of the author(s) and not those of the institute. Research disseminated by IZA may include views on policy, but the institute itself takes no institutional policy positions.

The Institute for the Study of Labor (IZA) in Bonn is a local and virtual international research center and a place of communication between science, politics and business. IZA is an independent nonprofit company supported by Deutsche Post World Net. The center is associated with the University of Bonn and offers a stimulating research environment through its research networks, research support, and visitors and doctoral programs. IZA engages in (i) original and internationally competitive research in all fields of labor economics, (ii) development of policy concepts, and (iii) dissemination of research results and concepts to the interested public.

IZA Discussion Papers often represent preliminary work and are circulated to encourage discussion. Citation of such a paper should account for its provisional character. A revised version may be available directly from the author. 
IZA Discussion Paper No. 1404

November 2004

\section{ABSTRACT \\ The Political Economy of Job Protection and Income Redistribution*}

This paper presents a model allowing to analyze voting, welfare institutions and economic performance. We consider a political economy framework with three classes of agents: entrepreneurs, employed workers and unemployed workers. Agents vote on alternative institutional options: the degree of labour market flexibility and the intensity of redistribution. We show that the welfare state configuration depends on the nature of the political system majoritarian, coalition, two-party. Because internationalization reduces the possibility for national government to effectively tax profits, the existing political coalition is fragilized by the process of globalization. The model generates results concerning the macroeconomic equilibrium employment level. Hence we can assess the effects of internationalization on macroeconomic performance. The impact of internalization depends on the nature of the political system (majoritarian versus coalition government) and on the institutional configuration (positive flexibility versus positive redistribution).

JEL Classification: $\quad$ 138, H55, J41, J65

Keywords: job security, redistribution, political equilibriums, unemployment

Corresponding author:

Donatella Gatti

CEPREMAP

142 rue de Chevaleret

75013 Paris

France

Email: donatella.gatti@cepremap.cnrs.fr

\footnotetext{
* The authors would like to thank Torben Andersen and the participants to the workshop "Globalization. Implications for labour market and welfare policies", Aarhus, 15-16 January, 2004 for comments on an earlier version of this paper.
} 


\section{Introduction}

This paper aims to develop an integrated framework to analyze voting, welfare institutions and economic performance. More particularly, we focus on the political economy of labour market institutions and income redistribution in a context of globalization.

The reason for doing so is that labour institutions and income redistribution are two main pillars of the welfare and social security systems. In this respect, Bertola and Boeri [2002] insist on the fact that a crucial trade-off structures social security systems: the trade-off between income protection (IP) through redistribution, and employment protection (EP) through legislation. The existence of such a trade-off can be confirmed by looking at empirical data for selected developed countries (Figure 2 in Bertola and Boeri, 2002). In fact, one can see that countries position themselves along the trade-off line, choosing a preferred combination of IP and EP. In this respect, it is frequently argued that internationalization induces pressures to undermine national social security systems. First, globalization threatens the role and strength of national regulations on job protection; second, economic actors holding mobile assets - such as capital - find themselves in a more comfortable position to exit national jurisdictions, thereby forcing policy makers to compete to preserve the national tax basis (Swank and Steinmo, 2002). We aim to propose an analytical framework encompassing both issues.

Two streams of literature mainly deal with issues related to welfare and social security systems: the economics and the political economy literatures. The former investigates the consequences of social security institutions on economic performance and restate the equity-efficiency dilemma (see for instance Bertola et al., 2001). In this respect, Bertola and Boeri [2002; p. 5] state that "broadly speaking, labour market institutions that protect workers against unfair market developments unavoidably reduce the intensity of competition as they trade-off lower productive efficiency against ex ante distributional equity". Hence, there would be a fundamentally perverse effect of equity improving institutions on economic performance.

The political economy literature studies the support for welfare policies stemming from interested voters (see for instance Moene and Wallerstein, 2001). One crucial question here is the multiplicity of welfare and social security models. Following the seminal contribution by Esping-Andersen [1990], Amable [2003] provides a review of existing taxonomies as well as an empirical analysis confirming the variety of welfare state models: the Scandinavian, the neoliberal, the continental European, the South-European and the Asian models. The main variables that can be used to distinguish among these models are: the weight of redistribution, the size of the public sector employment, the unions weight, the importance of employment regulation, the nature of pension schemes. Political institutions play a crucial role in 
shaping the evolution of welfare effort in developped democracies (Crepaz, 1998). In particular, Crepaz notes that "the more political power is dispersed, [...] the higher will be the representativeness and capacity of governments to respond to diffuse welfare state issues" (Crepaz, 1998, p. 63). More specifically, a wider government coalition can be pushed to increase welfare spending in order to rely upon larger welfare state resources to build a political compromise.

Few papers have attempted to bridge the gap between the political economy literature -dealing with the role and functioning of political and institutional systems- and the economic literature studying the determinants of macroeconomic performance. Persson, Roland and Tabellini [2003] attempt to analyze in an integrated setup the electoral system, government coalitions and economic policy. The authors' main result points to a link between the nature of the electoral system (majoritarian versus proportional) and the size of government spending. However, the paper does not address the issue of macroeconomic performance. Saint Paul [2001] provides an analysis of the political economy of labour market institutions and their impact on employment. The political process studied by the author portrays several economic groups (such as employed and unemployed workers) taking decisions over institutional reforms. These reforms are carried out on a single dimension, for instance job protection legislation. The political process itself does not allow for coalition and strategic interactions between the economic groups.

Our paper proposes a framework where three socio-economic groups interact and vote on several dimensions of the social security system at a time. Because the three groups have intrinsically contradictory preferences over the welfare state configuration, actors need to build a political compromise. The process by which a compromise emerges is a matter of political exchange between socio-economic groups. This includes the possibility of engaging in coalitions ensuring the majority of votes. Hence, the nature of the compromise crucially depends on the features of the prevailing political system: a majoritarian system yields a political equilibrium that is radically different from a coalition government system.

To analyze the process of compromise formation (and the associated political equilibrium), we develop a political economy framework based on a recent model proposed by Pagano and Volpin [2001]. Pagano and Volpin [2001] study the political economy of corporate governance in a three actor economy: entrepreneurs, workers and rentiers vote on two institutional dimensions, investments protection and job protection. Their model allows for the possibility that actors negotiate over alternative institutional options and form coalitions. As a consequence, the final political consensus will not necessarily correspond to any individual actor's first best.

We modify and extend Pagano and Volpin's framework to study the compromise concerning welfare state institutions that can emerge among socio-economic actors, and the way this compromise is modified following 
the process of internationalization. More specifically, three classes of actors will be considered: entrepreneurs, employed workers and unemployed workers. Alternative institutional options are identified by two parameters: the degree of labour market flexibility (regulation) and the intensity of welfare redistribution through taxes and benefits. Hence a vote on two institutional variables takes place, namely the proportion $f$ of workers that can be fired according to legislation and the tax rate $r$ determining wages and profits taxes. Our assumption is that internationalization makes it easier for firms to evade taxes thus reducing the size of national tax basis. The process leads to a modification of the political compromise and weakens existing coalitions.

In the next section, we present the basic set-up of the model. Section 3 outlines the preferences of each group of agents. Section 4 studies the political equilibria resulting from coalition formation and discusses the outcome in reference to known models of social security systems. The following section investigates the links between the political equilibrium and economic performance. Section 5 considers a particular case where there are two parties competing for votes. A final section concludes the paper and considers possible extensions.

\section{Basic framework}

Our model features three groups of economic actors: entrepreneurs, employed workers and unemployed workers. There is a fixed number $F$ of entrepreneurs. $F$ is large enough so that there is competition among firms. The total population is normalised to $1+F$ with $F<1$. Entrepreneurs can only manage a firm, and workers can only be employed or unemployed. Each entrepreneur manages a firm; all firms have an identical production function which uses labour as its sole input. $N$ represents the number of employed workers. Workers have incentives to provide an effort level equal to 1 with a utility cost of $e$; at time $t$ the value of labour productivity is $y_{t}$. Real wage rigidities due to an efficiency wage mechanism (see Section 5.1) generate equilibrium unemployment; $N_{u}$ is the number of unemployed workers as well as the unemployment rate (in fact $N+N_{u}=1$ ).

We consider that actors' political decisions are driven by economic motives; based on their utility and profit functions, workers and entrepreneurs express their preferences over alternative institutional options - i.e. various degrees of job security and welfare redistribution. Hence, economic actors need to take decisions in both the economic and the institutional dimensions. To help understand how these two dimensions interact in our setup, we follow Pagano and Volpin [2001] and consider a simple multiperiod model encompassing two production cycles, which allows us to consider job flows in and out of unemployment. 
The exact time line of our model is as follows:

$t=-1$ : employment contracts are signed determining wages $w_{1}$ and $w_{2}$ and employment level $N$;

$t=0$ : a political decision is taken on two dimensions, namely the degree of job security $(1-f)$ and welfare redistribution $(r)$;

$t=1$ : initial output is produced, initial wages $w_{1}$ and unemployment benefit $b_{1}$ are paid;

$t=1.5$ : productivity shock occurs; employment flows (firing and hiring) take place;

$t=2$ : final output is produced, second period wages $w_{2}$ and redundancy indemnities $\delta_{2}$ are paid.

Employment contracts are signed at $t=-1$ stating wages and the employment level. This stage sets up the political groups and determines their respective size. In the following period, political groups strike their institutional decisions through a voting process on two institutional parameters: the proportion $f$ of workers that can be fired at time $t$ as well as the tax rate $r$ on wages and profits. After voting, the first production cycle comes to an end. At time $t=1.5$, a shock takes place which makes a proportion $1-d$ of employed workers less productive - for instance by making their competence obsolete. Firms would like to get rid of unproductive workers to hire new personnel ${ }^{1}$. This can be done only up to a proportion $f$, fixed by law. Hence, the flow out of employment at time $t=1.5$ equals $N \cdot(1-d) \cdot f$. After workers reallocation has taken place, the second production cycle comes to a end.

Taxes are paid at time $t=1,2$ and used to finance unemployment benefit $b_{1}$ and redundancy indemnities $\delta_{2}$. At each period the balanced budget constraint holds; hence the size of benefits is endogenously determined at time $t=1,2$ by the following equations:

$$
\begin{aligned}
N_{u} \cdot b_{1}(r) & =T_{e}^{1}(r)+T_{f}^{1}(r) \\
N \cdot(1-d) \cdot f \cdot \delta_{2}(r) & =T_{f}^{2}(r)
\end{aligned}
$$

where $T_{f}^{t}(r)=$ taxes paid at period $t=1,2$ by $f$ irms and $T_{e}^{1}(r)=$ taxes paid at period $t=1$ by employed workers. Workers contribute to financing unemployment benefits but redundancy indemnities are entirely financed by firms.

The model will be solved by backward induction. After presenting utility and profits functions, we study political decisions at time $t=0$ and then the macroeconomic equilibrium at time $t=-1$.

\footnotetext{
${ }^{1}$ The implicit assumption here is that unemployed workers hold more up-to-date competence than unproductive workers. This is a common simplifying assumption in the literature on labour turnover.
} 


\section{1 workers utility}

Define $U_{e}^{t}$ the utility at time $t$ of an employed worker. We assume that unemployment benefits are paid only for one period at $t=1$ for first-period unemployed. This assumption corresponds to the empirical evidence that unemployment benefits are generally limited in time. The utility of a one period unemployed worker at time $t$ is $U_{u}^{t}$. A worker who was unemployed at period 1 and stays unemployed at period 2 is not entitled to any additional benefit. His utility at time 2 is $U_{l t u}^{2}$ and is equal to zero.

Recall that a shock takes place at time $t=1.5$ making a proportion $1-d$ of employed workers less productive. Hence, each worker faces a positive probability of losing his job. This probability depends on the job security legislation determining the size of employment adjustements admitted by law: firms can fire only up to a proportion $f$ of less productive workers. Workers who are fired after the productivity shock obtain redundancy indemnities $\delta_{2}(r)$.

Utilities at time $t=1$ are determined as follows:

$$
\begin{array}{cc}
w_{1}-r \cdot W-e+ \\
U_{e}^{1}= & {[d+(1-d) \cdot(1-f)] \cdot U_{e}^{2}+(1-d) \cdot f \cdot U_{u}^{2}} \\
U_{u}^{1}= & b_{1}(r)+a \cdot U_{e}^{2}+(1-a) \cdot U_{l t u}^{2}
\end{array}
$$

$w_{1}$ is the wage paid at $t=1, e$ is the effort level provided by the worker and $a$ is the hiring rate. $W$ is the maximum wage tax that can be taken out of wage income, i.e. corresponding to a tax rate $r=1$. We choose this expression for taxes out of simplicity reasons. The wage tax is non distortive, but its amount is chosen by voters, through the choice of $r$. We will suppose $W$ exogenous in the following. Hence, total wage tax revenues $T_{e}^{1}(r)$ are equal to $N \cdot r \cdot W$.

The hiring rate is such that the flow equilibrium condition holds at time $t=1.5$. One has:

$$
a \cdot N_{u}=f \cdot(1-d) \cdot N
$$

The utility of workers hired $\left(U_{e}^{2}\right)$, fired $\left(U_{u}^{2}\right)$ and long term unemployed $\left(U_{\text {ltu }}^{2}\right)$ at time $t=2$ are the following:

$$
\begin{aligned}
U_{e}^{2} & =w_{2}-e \\
U_{u}^{2} & =\delta_{2}(r) \\
U_{l t u}^{2} & =0
\end{aligned}
$$




\section{2 firms profits}

Let $V^{1}$ be the value of a firm at time $t=1$. This value is given by the net output per worker $\pi_{t}$ of both production cycles at time $t=1,2$. It includes profit tax costs as well as employment reallocation flows at time $t=1.5$ :

$$
\begin{aligned}
V^{1} & =\left(\pi_{1}+\pi_{2}\right) \cdot \frac{N}{F} \\
\pi_{1} & =y_{H}-w_{1}-(1-\varepsilon) \cdot r \cdot T \\
\pi_{2} & =[d+(1-d) \cdot f] \cdot\left(y_{H}-w_{2}\right)+(1-d) \cdot(1-f) \cdot\left(y_{L}-w_{2}\right)-(1-\varepsilon) \cdot r \cdot T
\end{aligned}
$$

As in Pagano and Volpin [2001], $y_{H}$ is the productivity level of highly productive workers, $y_{L}$ is the level of low productivity workers. For the first production cycle, every worker has the high productivity level. Following the shock that takes place at $t=1.5$, a proportion $1-d$ of the workers becomes less productive, i.e. their productivity level falls to $y_{L} . T$ is the maximum tax revenue out of profits, corresponding to $r=1$. We suppose $W<T$. The tax on firms acts as an employment tax so that total tax levied on profits is proportional to employment.Profit tax revenues $T_{f}^{t}(r)$ at time $t=1,2$ are $N \cdot(1-\varepsilon) \cdot r \cdot T$.

The parameter $\varepsilon$ measures the intensity of internationalization, which makes possible for firms to evade such taxes. Following Avi-Yonah [2000], we consider that the current age of globalisation may be characterised by an increased mobility of capital, both as a result of technological change (the ability to move funds electronically) and the relaxation of international capital controls. This has implication for tax competition and tax revenues. Countries lower their personal and corporate tax rate in order to attract foreign funds, which unleashes a race to the bottom in terms tax rates. At the same time, firms established on an multinational base have better opportunities to shift profits in order to take advantages of tax competition. Bartelsman and Beetsma [2000] report that a unilateral increase in the corporate tax rate leads to a more than offsetting decline in reported profits and thereby in corporate tax basis. In its 22nd Report to the President, the French Tax Council reports that firms' reaction to the tax competition induced by globalization is not so much to move capital and relocate production units, but to keep production in their original locations and merely shift profits to places where the tax rates are the lowest (Conseil des impôts [2004]). Therefore, internationalization and the ability to levy tax on corporations are linked. ${ }^{2}$ We simply represent this link with the help of

\footnotetext{
${ }^{2}$ The relationship between globalization and corporate tax rates is established from an empirical point of view as stated for instance by Swank and Steinmo [2002]. However, the same authors provide empirical results supporting the idea that the effective rate of tax on capital would be much less sensible to the degree of internationalization. See Swank and Steinmo [2002] for an appraisal of the literature underlining the debate between those who support and those who oppose the "globalization theory".
} 
the parameter $\varepsilon$. An increase in internationalization allows firms to evade taxation, so that for a given tax $r \cdot T$, only a fraction $(1-\varepsilon)$ is actually paid. Our model will allow us to deduct the consequences of this possibility offered to firms for taxation decided within the country.

\section{Political preferences of socio-economic groups}

Political preferences at time $t=0$ are determined by the values of employed and unemployed workers' utility and firms' profit at time $t=1$. Because wages are set at time $t=-1$, they are taken as given at time $t=0$ when political choices are made. Hence, in this section and the following we analyze the political decisions for given values of wages $w_{1}$ and $w_{2}$. Section 5 will present the wage setting process and the macroeconomic equilibrium.

\section{1 employed workers}

To determine employed workers political preferences, we have to go back to equation (3) defining workers utility at time $t=1$. By substituting equations (2), (7) and (6) into (3) and taking account of the definition of tax income, one obtains an expression for workers utility at $t=1$ as a function of institutional parameters $f$ and $r$. Hence, political preferences are simply determined by the partial derivatives of $U_{e}^{1}$ with respect to the two institutional parameters. One has:

$$
\begin{aligned}
& \frac{\partial U_{e}^{1}}{\partial f}=-\left(w_{2}-e\right) \cdot(1-d)<0 \\
& \frac{\partial U_{e}^{1}}{\partial r}=(1-\varepsilon) \cdot T-W\left\{\begin{array}{l}
>0 \text { if } \varepsilon<1-\frac{W}{T} \\
<0 \text { if } \varepsilon>1-\frac{W}{T}
\end{array}\right.
\end{aligned}
$$

Workers are generally opposed to flexibility. In other words, they appreciate labour market regulation protecting existing jobs and thus reducing the probability of being fired. Regarding taxes, one can see that the intensity of internationalization determines employed workers' preferences over redistribution. When internationalization is weak, firms' profits are more easily taxed and firms contribute largely to redistribution. Hence, workers can benefit from unemployment benefits in case of firing without having to support the entire burden of compensation transfers towards the unemployed. As internationalization becomes stronger, firms' profits become more volatile and the profit tax base shrinks. The burden of redistribution falls more heavily on workers who eventually become opposed to taxes and redistribution. 


\section{2 unemployed}

Political preferences of unemployed are determined by their utility at time $t=1$ i.e. by equation (4). Again, one has to substitute equations (1), (6) and (8) into (4) and take account of the definition of tax income. This yields an expression of unemployed utility that depends only on institutional parameters. The unemployed political preferences are determined by the sign of the partial derivatives of $U_{u}^{1}$ with respect to $f$ and $r$. One obtains:

$$
\begin{aligned}
\frac{\partial U_{u}^{1}}{\partial f} & =\left(w_{2}-e\right) \cdot(1-d) \cdot \frac{N}{N_{u}}>0 \\
\frac{\partial U_{u}^{1}}{\partial r} & =[(1-\varepsilon) \cdot T+W] \cdot \frac{N}{N_{u}}>0
\end{aligned}
$$

Unemployed workers generally appreciate labour market flexibility i.e. low regulation. In fact, flexibility allows for larger flows on the labour market thus increasing the probability of job finding. ${ }^{3}$ The unemployed unambiguously support taxes as they serve to finance redistribution through the unemployment benefits scheme.

\section{3 entrepreneurs}

Entrepreneurs' political preferences are determined by the firm's value at time $t=1$. This value is given by equation (9). The partial derivatives with respect to $f$ and $r$ can be written as follows:

$$
\begin{aligned}
& \frac{\partial V^{1}}{\partial f}=\left(y_{H}-y_{L}\right) \cdot(1-d) \cdot \frac{N}{F}>0 \\
& \frac{\partial V^{1}}{\partial r}=-2 \cdot(1-\varepsilon) \cdot T \cdot \frac{N}{F}<0
\end{aligned}
$$

Firms' value increases when labour market regulation is less strict. In fact, this allows firms to get rid of a larger proportion of less productive workers at time $t=2$. Entrepreneurs thus favour flexibility. Entrepreneurs are generally opposed to taxes as they are asked to contribute to redistribution, without directly benefiting from it.

\section{4 divergent political preferences}

We summarize our results on political preferences in the table below.

\footnotetext{
${ }^{3}$ One should note that this is a partial equilibrium result, obtained for given values of wages and employment. The macroeconomic result is much more complex and is derived in Section 5 and following.
} 


\begin{tabular}{|l|c|l|}
\hline & $f$ & $r$ \\
\hline workers & - & $+/-$ \\
\hline unemployed & + & + \\
\hline entrepreneurs & + & - \\
\hline
\end{tabular}

Table 1 : political preferences

Workers are opposed to labour flexibility as a group because they have to choose a degree of employment protection not knowing whether their productivity level will be high or low during the second production cycle. Every worker has a positive probability of having a low productivity and runs the risk of being fired if no legal employment protection measures are implemented. Ex post, high productivity workers would be indifferent with respect to employment protection since they would not be under the threat of redundancy. But low-productivity workers would press for a maximum employment protection. Ex-ante, the average worker would vote for this maximum protection. The unemployed are opposed to employment protection for opposite reasons. Their only chance of finding a job is that low productivity workers should be fired. The easier it is for firms to lay off workers, the higher is the unemployed's probability of finding a job. In this case, their interests are perfectly in line with those of firms, who would wish to replace low-productivity workers with high-productivity unemployed. But unemployed and firms' interests are exactly opposite as far as taxation and redistribution are concerned. Taxation is a mere cost for firms, which decreases profits and brings no benefits. For unemployed, it is a source of income since unemployment benefits are financed through taxation. Therefore, entrepreneurs would vote for a zero-rate of taxation, whereas unemployed would choose the maximum rate.

The preferences of workers with respect to taxation and redistribution are ambiguous. Taxation is a sum taken off their wage income, and on this count, they are opposed to it. On the other hand, tax income finances redundancy indemnities which they might claim should their productivity level lead to their dismissal before the second production period. And since tax revenues come from both wage and profits, their benefits will not be entirely financed by them. However, the possibility for firms to evade taxation -thanks to internationalization- makes it more difficult to finance benefits. When the tax evasion possibilities are high, the profit tax base is very small and the bulk of tax revenues comes from wages. In this case, workers do not find it worthy to finance the unemployed of the first period since the benefits they might claim, during the second production period, will be financed by the profit tax alone, which will yield very little. Therefore, there exists a threshold degree of internationalization above which workers are opposed to taxation. Under this threshold level, the profit-tax base is large enough to make workers accept to finance the benefits of first period unemployed and, in return, have their own benefits financed by the profit tax revenues. 
In what follows we will restrict ourselves to the case where workers favour redistribution, i.e. $\varepsilon<1-\frac{W}{T}$.

\section{Voting and coalitions}

The political preferences characterized above shape the political decisions of socio-economic groups, which in turn determine the degree of flexibility and redistribution, i.e. the institutional setting.

Political decisions are taken on the basis of a voting process. The outcome of voting is determined by the majority of voters - i.e. the choice that collects the support of two classes out of three. We exclude the possibility of an unemployment rate so high that the unemployed could be a majority of voters by themselves, i.e. $N_{u}<\frac{1+F}{2}$. We also exclude the case where workers can by themselves achieve a majority, that is $1-N_{u}<\frac{1+F}{2} .{ }^{4}$ Actors may either vote on each single institutional dimension in turn (disjoint vote) or on both institutional dimensions at a time (joint vote). This second political system favors the emergence of coalitions among different classes having opposite preferences. These coalitions determine a political issue that configures an "institutionalized compromise".

A critical parameter to understand the outcome of the political process is internationalization, measured by $\varepsilon$. In fact, the intensity of internationalization determines employed workers preferences concerning redistribution. When intensity of internationalization is not too large, i.e. $\varepsilon<1-W / T$, workers are in favour of redistribution: $\frac{\partial U_{e}^{1}}{\partial r}>0$. In this case, the result of a majority vote is as follows: workers and unemployed vote for redistribution; entrepreneurs and unemployed vote for flexibility. Hence, the institutional setting is characterized by a flexible labour market complemented by a system of compensation transfers towards the unemployed. This is the outcome preferred by the unemployed.

\section{1 insiders coalition}

The majority vote leads to a configuration preferred by the unemployed, while workers and entrepreneurs are only partially satisfied. Employed workers and entrepreneurs can try to improve their respective welfares by forming a coalition. The coalition is only possible when the political system allows for the possibility of a joint vote on an "institutional platform", i.e. on the two institutional parameters at a time. If this is the case, a coalition can be formed with workers and entrepreneurs fixing through a bargaining process the values of the institutional parameters $f$ an $r$ - which will then be subject to a vote.

\footnotetext{
${ }^{4}$ See Appendix for parametrical conditions.
} 
To avoid cycling in voting, we consider, as in Pagano and Volpin [2001], that coalitions are formed once and for all. The political process can be represented as a four stage process: at stage 1 a coalition is formed by any two social groups, any group can participate to at most one coalition - if no coalitions are formed stage 4 follows; at stage 2 the coalition presents its proposal concerning institutional setting, each coalition presenting at most one proposal - if no proposal is presented stage 4 follows; at stage 3 social groups take a "yes or no" vote on the proposal according to a majority rule, if the proposal is accepted the political game is over - if no agreement is reached stage 4 follows; at stage 4 a disjoint vote takes place.

To verify that a coalition is indeed possible one should check the relative slope of workers and entrepreneurs indifference curves. Given their political preferences, it is clear that the two indifference curves have a positive slope. A coalition can be formed if it ensures a utility level higher than the majority vote outcome $\{f=1, r=1\}$. Figure 1 below portrays a situation where a coalition is possible.

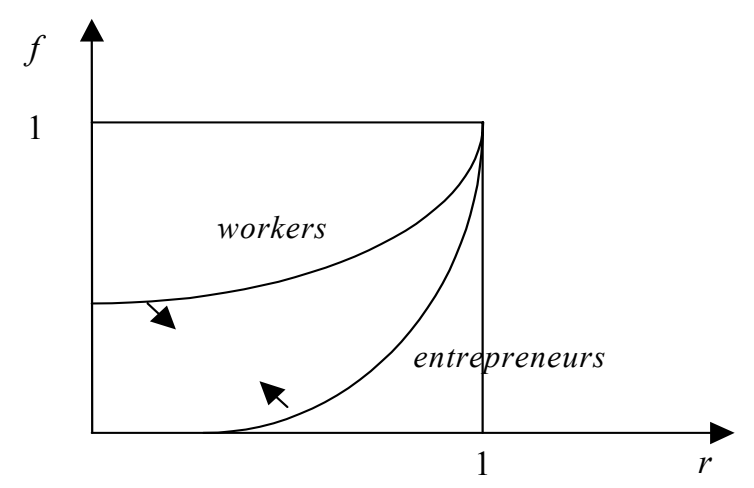

Figure 1. Entrepreneurs and workers indifference curves

Workers' and entrepreneurs' respective utilities increase in the directions given by the arrows in Figure 1. As it can be seen, for a coalition to be possible the entrepreneurs indifference curve should be more sloped than the workers indifference curve. This condition is indeed always satisfied in our model. In fact, the ratio of the slopes of the indifference curves (entrepreneurs/workers) is given by:

$$
\frac{2 \cdot T \cdot\left(w_{2}-e\right) \cdot(1-\varepsilon)}{\left(y_{H}-y_{L}\right) \cdot[(1-\varepsilon) \cdot T-W]}>1
$$

$$
\text { because } y_{H}-y_{L}<w_{2}-e^{5} \text { and }(1-\varepsilon) \cdot T-W<2 \cdot(1-\varepsilon) \cdot T \text {. }
$$

\footnotetext{
${ }^{5}$ This condition is necessary to ensure that firms are not willing to get rid of their entire workforce (in spite of regulation) by assuring compensation transfers to workers that can not be fired. This would be possible if the gain in terms of increased productivity is higher that the cost of the compensation transfers. To make voluntary departs possible, these
} 


\section{2 institutional setting}

The institutional parameters are fixed according to a bargaining process within the coalition. As Pagano and Volpin [2001], we assume that the result of such a bargaining is characterized by the Nash bargaining solution. Given that the outside option is the utility associated to the majority vote outcome $\{f=1, r=1\}$, the objective function of the coalition is the following:

$S=(1-\phi) \cdot\left\{\log \left[U_{e}^{1}(f, r)-U_{e}^{1}(1,1)\right]\right\}+\phi \cdot\left\{\log \left[V^{1}(f, r)-V^{1}(1,1)\right]\right\}$

where $\phi$ represents the bargaining power of entrepreneurs within the coalition.

The values of $f$ and $r$ are fixed by maximizing the above objective function. It can be shown that in our model the solutions are at the boundary, with either $r$ or $f$ equal to zero: if $\frac{\partial S}{\partial r}=0$ then $\frac{\partial S}{\partial f}<0$ and $f=0$; if $\frac{\partial S}{\partial f}=0$ then $\frac{\partial S}{\partial r}<0$ and $r=0$.

This yields two alternative sets of solutions, $S_{1}$ and $S_{2}$ :

$$
\begin{gathered}
S_{1}\left\{\begin{array}{l}
f=0 \\
r=r^{*}=1-\frac{1}{2} \cdot(1-d) \cdot\left[\frac{\left(y_{H}-y_{L}\right) \cdot(1-\phi)}{(1-\varepsilon) \cdot T}+\frac{2 \cdot\left(w_{2}-e\right) \cdot \phi}{(1-\varepsilon) \cdot T-W}\right]
\end{array}\right. \\
S_{2}\left\{\begin{array}{l}
f=f^{*}=1-\frac{T \cdot(1-\varepsilon) \cdot 2 \cdot\left(w_{2}-e\right) \cdot(1-\phi)+[(1-\varepsilon) \cdot T-W] \cdot\left(y_{H}-y_{L}\right) \cdot \phi}{\left(w_{2}-e\right) \cdot\left(y_{H}-y_{L}\right) \cdot(1-d)} \\
r=0
\end{array}\right.
\end{gathered}
$$

One can show that $\frac{d r^{*}}{d \varepsilon}<0$ and $\frac{d f^{*}}{d \varepsilon}>0$. Internationalization therefore leads to a modification of the institutional setting supported by the coalition, leading to more flexibility and less redistribution. The rationale for this result is that an increase in $\varepsilon$ corresponds to an increase in the outside option of entrepreneurs, i.e. the value of the firm associated with the institutional configuration corresponding to the majority vote. In fact, in that case the tax rate is at its maximum. Because an increase in $\varepsilon$ leads to more tax evasion by firms, the gain (in terms of lower taxation) from internationalization is relatively higher when the tax rate is high. This process continues up to the point where internationalization is sufficiently strong to modify workers preferences concerning redistribution.

Moreover, it can be shown that $\frac{d r^{*}}{d \phi}<0$ and $\frac{d f^{*}}{d \phi}>0$. Therefore, the impact of an increase in entrepreneurs bargaining power is similar to internationalization.

transfers should be equal to the second period utility of employed workers, i.e. $w_{2}-e$. 


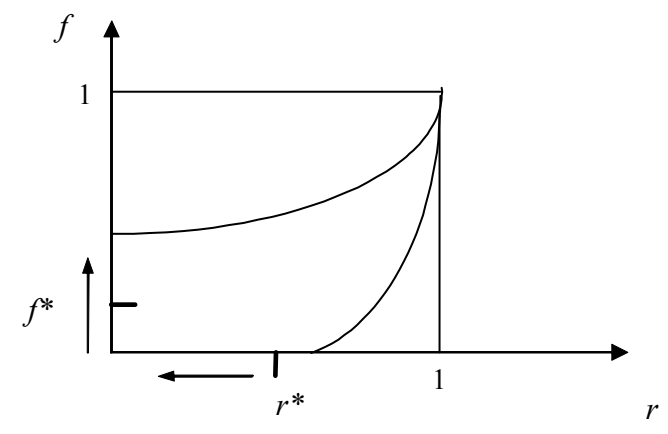

Figure 2. Consequences of increased internationalization and/or increased bargaining power of entrepreneurs

\section{3 different models in perspective}

The political equilibriums emerging out of the model give three possible institutional configurations.

\subsection{1 the 'flexicurity' model}

This configuration associates labour market flexibility and redistribution: $f=1$ and $r=1$. Such an equilibrium emerges when there is a majoritarian political system and corresponds to the unemployed' first best. Such a combination has been dubbed 'flexicurity' (Esping Andersen, 2002; Visser et Hemerijck, 1999) in the case of Northern European economies such as the Netherlands or Denmark. This setting is held to combine the qualities of easy labour market adjustments with those of a high social protection. Our model shows that this configuration is only viable if globalisation forces are not too strong $\left(\varepsilon<1-\frac{W}{T}\right)$. Otherwise employed workers vote against redistribution and the majoritarian system leads to a neo-liberal configuration with full labour market flexibility and no redistribution $f=1$ and $r=0$.

\subsection{2 the 'Anglo-saxon' model}

This configuration combines labour market flexibility $\left(f=f^{*}>0\right)$ and no redistribution $(r=0)$ and can be associated with the 'Anglo-saxon' economies (USA, UK). ${ }^{6}$ The degree of labour market flexibility depends on the different parameters of the model, particularly the bargaining power of firms. It may be noted that labour market flexibility increases with globalisation.

\footnotetext{
${ }^{6}$ See Amable [2003] for a characterisation of the market-based neo-liberal model.
} 


\subsection{3 the (South-)European model}

Some degree of labour market rigidity associated with some redistribution is a characteristic of European economies (Amable, 2003). North European economies generally favour a high degree of social protection through redistribution rather than labour market flexibility. Countries like France or Germany (the continental European model) are less generous with respect to redistribution, but protect more employed workers. The case of a high degree of job protection and a limited redistribution corresponds to South European countries such as Spain. In this respect, the last possible configuration of our model, which combines labour market rigidity $(f=0)$ with some redistribution $\left(r=r^{*}>0\right)$, is close to the South-European model. Increased globalisation leads to a drop in the amount of redistribution.

\section{Economic equilibrium and performance}

In this Section, we consider the macroeconomic equilibrium with endogenous wages at time $t=-1$. One again, we restrict our attention to the case of weak internationalization, i.e. the case where workers are favourable to taxation and redistribution $\left(\varepsilon<1-\frac{W}{T}\right)$.

\section{1 efficiency wages}

We endogenize the determination of the wage rates for each production period. We suppose an efficiency wage mechanism à la Shapiro and Stiglitz [1984]. Working involves an effort cost $e$ for the worker, who has a possibility to shirk. A shirking worker is caught with probability $p$ and fired immediately.

Let us first determine the efficiency wage for the second production cycle. Since production stops after this cycle, a worker caught shirking during the second production period ends up unemployed with no further chance of getting another job. Denoting by $U_{u s}^{2}$ the utility of a fired shirker, we can express the equations describing the value of shirking at $t=2$ :

$$
U_{e s}^{2}=(1-p) \cdot w_{2}+p \cdot U_{u s}^{2}
$$

and the value of not shirking:

$$
U_{\text {ens }}^{2}=w_{2}-e
$$

A worker fired for shirking does not obtain any redundancy indemnity, therefore $U_{u s}^{2}=0$. We may then deduce the efficiency wage for the second production period:

$$
w_{2}^{e}=\frac{e}{p}
$$


We can now turn to the wage rate for the first production period. The utility of a shirker can be expressed by the following equation:

$$
U_{e s}^{1}=(1-p) \cdot\left\{\begin{array}{c}
w_{1}-r \cdot W+[d+(1-f) \cdot(1-d)] \cdot U_{e}^{2} \\
+f \cdot(1-d) \cdot U_{u}^{2}
\end{array}\right\}+p \cdot U_{u}^{1}
$$

One can note that a shirker fired during the first production cycle is entitled to the benefits paid to every unemployed worker $\left(b_{1}\right)$; his utillity is thus equal to $U_{u}^{1}$. The utility of a nonshirker is:

$$
U_{\text {ens }}^{1}=w_{1}-r \cdot W-e+[d+(1-f) \cdot(1-d)] \cdot U_{e}^{2}+f \cdot(1-d) \cdot U_{u}^{2}
$$

Taking account of the fact that benefits and redundancy indemnities are financed by tax income according to (1) and (2), and recalling that $N+N_{u}=1$, we obtain the efficiency wage for the first production period:

$$
w_{1}^{e}=\frac{e \cdot\left[f \cdot(1-p) \cdot(1-d)+p \cdot N_{u}\right]+p \cdot r \cdot\left[W+T \cdot(1-\varepsilon) \cdot\left(1-2 \cdot N_{u}\right)\right]}{p \cdot N_{u}}
$$

One can see that the efficiency wage increases with labour market flexibility $f$. An increased $f$ is equivalent to a rise in workers turnover, which diminishes the value of being employed, thus decreasing incentives to provide the adequate level of effort. In order to offset such an effect, the efficiency wage ought to be raised. The effect of the tax rate $r$ is positive when the unemployment rate is under $50 \%$. This is due to the fact that the tax rate determines the generosity of the unemployment benefits and redundancy indemnities. Increased benefits going to the unemployed increase the value of being unemployed thus decreasing incentives not to shirk. Hence, here again the efficiency wage must rise. Internationalization $\varepsilon$ pushes the efficiency wage downwards because it reduces the tax base and the level of unemployment benefits.

\section{2 zero profit condition}

Since the number of firms is fixed, there is no free entry condition that would drive profits to zero. However, as long as there are positive profits, firms are willing to increase their labour force. Hence, competition among firms will push up labour demand and thereby wages to the point where the equilibrium wage corresponds to a profit level equal to zero, under the constraint of the efficiency wage. We can use this condition to derive an expression for the wage rate of the first production period compatible with a zero profit condition:

$$
w_{1}^{Z P}=(1+d) \cdot y_{H}+(1-d) \cdot\left[(1-f) \cdot y_{L}+f \cdot y_{H}\right]-2 \cdot r \cdot T \cdot(1-\varepsilon)-\frac{e}{p}
$$


$w_{1}^{Z P}$ decreases with $r$ but increases with $f$ and $\varepsilon$.

\section{3 employment}

We can derive the level of equilibrium employment by crossing the efficiency wage schedule and the zero profit condition. Because (17) and (18) also depend on the institutional variables $f$ and $r$, employment will depend on the outcome of the political process and of the bargaining process within the coalition.

\subsection{1 case 1 . flexicurity}

This case corresponds to the majoritarian outcome with $r=1, f=1$. The unemployment rate is easily derived and equals:

$$
N_{u}=\frac{(1-d) \cdot(1-p) \cdot e+p \cdot[T \cdot(1-\varepsilon)-W]}{2 \cdot p \cdot y_{H}-e \cdot(1+p)}
$$

It should be noted that $2 \cdot p \cdot y_{H}-e \cdot(1+p)>0$ given the parametrical restrictions that we consider below (case 3 ). Globalization has a positive effect on employment as long as $\varepsilon<1-\frac{W}{T}$. However, an increase of $\varepsilon$ below this value will imply a change of the majoritarian political equilibrium and the associated unemployment rate.

\subsection{2 case 2 . positive flexibility}

This scenario corresponds to the solution $S_{2}$ with $r=0, f=f^{*}$. We can compute the value of the efficiency wage $w_{1}^{e}$ with $r=0$ and $f=f^{*}$. Taking account of the expression of $w_{2}^{e}$ and rewriting (17), we can deduce an expression for the unemployment rate $N_{u}\left(w_{1}, \varepsilon\right)$.

$$
N_{u}=\frac{e \cdot(1-p) \cdot\left[(1-d) \cdot\left(y_{H}-y_{L}\right)-2 \cdot T \cdot(1-\varepsilon) \cdot(1-\phi)\right]}{-p \cdot\left(y_{H}-y_{L}\right) \cdot[T \cdot(1-\varepsilon)-W] \cdot \phi}
$$

One can check that ceteris paribus, an increased $\varepsilon$ pushes the unemployment rate up:

$$
\frac{\partial N_{u}}{\partial \varepsilon}>0
$$

One can also easily check that $\frac{\partial N_{u}}{\partial w_{1}}<0$. Since in equilibrium $w_{1}=w_{1}^{Z P}$, which depends only on $\varepsilon$, we obtain the equilibrium value of the unemployment rate $N_{u}(\varepsilon)$. The effects of an increase in $\varepsilon$ on the rate of unemployment can be assessed: 


$$
\frac{d N_{u}}{d \varepsilon}=\frac{\partial N_{u}}{\partial w_{1}} \cdot \frac{d w_{1}}{d \varepsilon}+\frac{\partial N_{u}}{\partial \varepsilon}
$$

Since $\frac{\partial N_{u}}{\partial w_{1}}<0, \frac{d w_{1}}{d \varepsilon}>0$ and $\frac{\partial N_{u}}{\partial \varepsilon}>0$, there is in principle an indeterminacy. However, one can show that the sign of this derivative depends on the sign of the term $y_{H} \cdot(1+d)+y_{L} \cdot(1-d)-e \cdot \frac{1+p}{p}$. As the analysis of case 3 will show, in order to have an equilibrium this term must be positive. Hence, an increase in internationalization leads to a rise in unemployment.

\subsection{3 case 3. positive redistribution}

This case corresponds to the set of solution $S_{1}$ with $r=r^{*}, f=0$. We can compute the value of the efficiency wage $w_{1}^{e}$ and the zero-profit wage $w_{1}^{Z P}$ with $r=r^{*}$ and $f=0$. One can check that:

$$
\begin{aligned}
\frac{d w_{1}^{Z P}}{d \varepsilon} & =\frac{\partial w_{1}^{Z P}}{\partial \varepsilon}+\frac{\partial w_{1}^{Z P}}{\partial r} \cdot \frac{d r}{d \varepsilon}>0 \\
\frac{d w_{1}^{e}}{d \varepsilon} & =\frac{\partial w_{1}^{e}}{\partial \varepsilon}+\frac{\partial w_{1}^{e}}{\partial r} \cdot \frac{d r}{d \varepsilon}<0
\end{aligned}
$$

because $\frac{d r}{d \varepsilon}<0, \frac{\partial w_{1}^{Z P}}{\partial \varepsilon}>0, \frac{\partial w_{1}^{Z P}}{\partial r}<0, \frac{\partial w_{1}^{e}}{\partial \varepsilon}<0$ and $\frac{\partial w_{1}^{e}}{\partial r}>0$ as long as the unemployment rate is lower than $50 \%$. This leads to a situation where increased internationalization pushes firms labour demand upward and the efficiency wage schedule downward, which yields a positive impact on employment as shown in Figure 3.

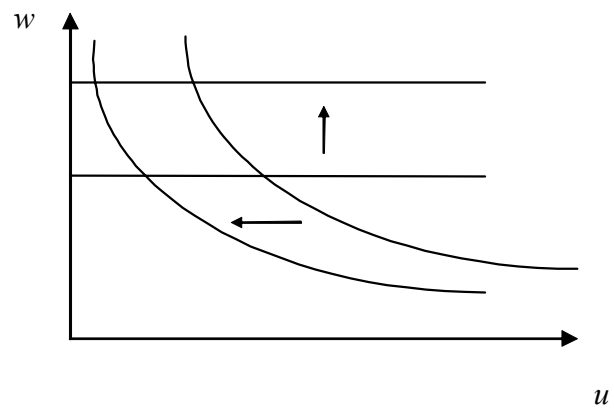

Figure 3. Impact of increased internationalization

One should note that the sign of $\frac{d N_{u}}{d \varepsilon}$ is that of $-\left[y_{H} \cdot(1+d)+y_{L} \cdot(1-d)-e \cdot \frac{1+p}{p}\right]$. Because we know from Figure 3 that $\frac{d N_{u}}{d \varepsilon}<0$ we conclude that the sign of this term must be negative. 


\section{4 discussion}

The results above suggest that increasing globalization affects in a different way the institutional configurations corresponding to the three social security systems (see Figure 4).

Concerning flexicurity (case 1) and positive redistribution (case 3, close to the South-European model), globalization yields fiscal restraint by reducing the corporate tax base; in case 3 this is associated to a negotiated reduction in the level of the tax rate. This evolution corresponds to a process of "social dumping" leading to a weakening of the redistributive role of the welfare state. The effects of such a process on employment are positive. The reason is that taxes bear a the negative impact on labour demand, and unemployment benefits increase the efficiency wage level. Fiscal restraint and weaker redistribution are thus associated with higher labour demand and lower efficiency wage. We suspect that such results might be sensitive to changes in the setup of the model. In particular, redistribution matters more for economic performance if one takes account of the unemployed human capital and of the quality of job matches.

Concerning the positive flexibility scenario (case 2), globalization leads to an increasing level of labour market flexibility, which yields a negative impact on employment. The reason is that job security acts as an incentive device thus allowing to lower the efficiency wage schedule. Hence, increased flexibility creates real wage pressure, which may lower aggregate employment (see Amable and Gatti, 2004). This result points to one possible weakness of the Anglo-Saxon model of markets deregulation.

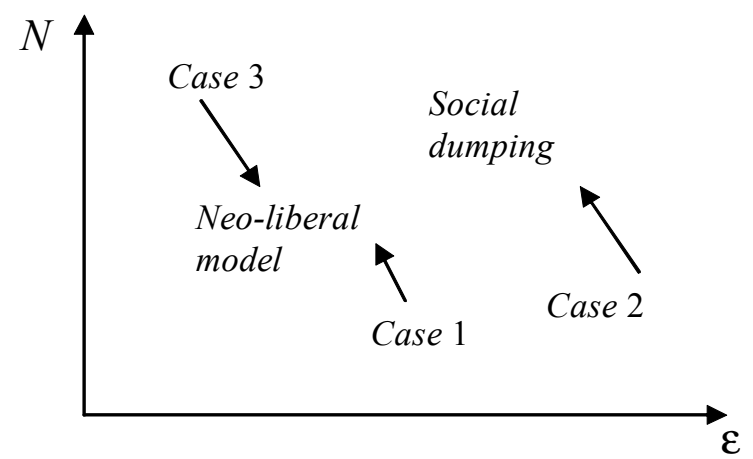

Figure 4. Effects of globalization on employment and social security in the three cases 


\section{Political equilibrium with two-party competi- tion}

We have considered so far situations where the agenda of each party was suited to specific interest groups. We now turn to the situation where two parties compete for votes. Each party has no definite platform and modifies its offers to voters according to what program is more likely to attract voters. Probabilistic voting allows to escape from the problems associated to multidimensional voting problems (Persson and Tabellini, 2000). Each party is uncertain about the preferences of the voters, for instance because individual voters may abstain from voting for parties with platforms too far away from their ideal points. The expected number of votes is a smooth function of the policy platform. Parties are labelled 1 and 2. Voter $i$ belonging to social group $J(J=F, W, U)$ will prefer party 1 to party 2 if:

$$
U_{1}^{J}>U_{2}^{J}+\sigma^{i J}+\xi
$$

where $U_{1}^{J}$ is the utility of any member of group $J$ if party 1 wins, and $U_{2}^{J}$ the utility of the same group if party 2 wins. $\sigma^{i J}$ is an individual-specific parameter uniformly distributed over $\left[-\frac{1}{2 \cdot \phi_{J}}, \frac{1}{2 \cdot \phi_{J}}\right], \phi_{J}>0$ is a group specific parameter. $\xi$ measures the average relative popularity of party 2 in the population as a whole. This parameter too can take positive as well as negative values and is uniformly distributed over $\left[-\frac{1}{2 \cdot \psi}, \frac{1}{2 \cdot \psi}\right], \psi>0$. Given those assumptions, the vote share of party 1 is given by:

$$
p_{1}=\sum_{J} \alpha^{J} \cdot \phi_{J} \cdot\left(\sigma^{J}+\frac{1}{2 \cdot \phi_{J}}\right)
$$

where $\alpha^{J}$ is the relative share of group $J$ in the electorate and $\sigma^{J}$ characterises the 'swing voter' in group $J$, i.e. the voter whose bias makes him indifferent between the two parties. Therefore, the probability that party 1 wins the election is given by:

$$
\Pi_{1}=\frac{1}{2}+\frac{\phi}{\psi} \cdot \sum_{J} \alpha^{J} \cdot \phi_{J} \cdot\left(U_{1}^{J}-U_{2}^{J}\right)
$$

where $\phi=\sum_{J} \alpha^{J} \cdot \phi_{J}$ is the average density across groups.

In equilibrium, each party chooses the same platform, and thereby offers the same utility levels to each social groups. Maximising $\Pi_{1}$ (or $\left.\Pi_{2}\right)$ with respect to $r$ and $f$ gives the platform offered by the two parties. One can check that: 


$$
\begin{aligned}
& \frac{d \Pi_{1}}{d f}>0 \Leftrightarrow \phi_{F} \cdot\left(y_{H}-y_{L}\right)+\left(\phi_{U}-\phi_{W}\right) \cdot\left(w_{2}-e\right)>0 \\
& \frac{d \Pi_{1}}{d r}>0 \Leftrightarrow T \cdot(1-\varepsilon) \cdot\left(\phi_{U}+\phi_{W}-2 \cdot \phi_{F}\right)+W \cdot\left(\phi_{U}-\phi_{W}\right)>0
\end{aligned}
$$

$\frac{d \Pi_{1}}{d f}$ is always positive when $\phi_{U} \geq \phi_{W}$; it tends to stay positive when $\phi_{W}$ is not too large. In this case, the outcome is that parties propose labour market flexibility. This outcome is not surprising considering the preferences of each group with respect to flexibility. Only workers are against it. Parties are more likely to propose employment protection if workers' voting behaviour becomes more uncertain, that is if they become a 'swing group'. If $\phi_{W}$ is very high, this means that the group of workers is 'ideologically' more homogeneous and has a large number of swing voters. This makes the group itself more attractive for the parties, which therefore target their platforms towards the interests of this group.

The decision regarding redistribution depends on the extent of 'globalisation', $\varepsilon$, and on $T$ and $W$. In our setting, $\varepsilon<1-\frac{W}{T}$. this means that $\frac{d \Pi_{1}}{d r}$ increases with both $\phi_{U}$ and $\phi_{W}$ and it decreases with $\phi_{F}$. Here again, an increase in homogeneity of a group tends to tilt party platforms towards the interests of this group. The impact of $\varepsilon$ on party choices depends also on groups homogeneity. $\frac{d \Pi_{1}}{d r}$ increases with $\varepsilon$ when $\frac{\phi_{U}+\phi_{W}}{2}<\phi_{F}$, i.e. when the average density of workers and unemployed is lower than firm owners' density.

\section{Conclusion}

This paper has presented a model formalizing the link between the political system, the political power of socio-economic groups, the institutional configuration of the welfare state, and macroeconomic performance. We have considered three social groups - employed workers, unemployed workers and entrepreuneurs- having different political and economic interests. Social groups can affect the institutional framework - i.e. labour market flexibility and income redistribution - through a political process leading to voting.

Our main results show that the welfare state configuration is affected by the nature of the political system - majoritarian, coalition, two-party. A majoritarian system is characterized by an welfare state configuration associating a flexible labor market and a maximum level of redistribution. A coalition system features an "insiders" coalition (employed workers plus entrepreneurs) sustaining either positive flexible (and no redistribution) or positive redistribution (and no flexibility). Finally, the two-party system gives political power to the "swing voters" group. 
We have also studied the impact of internationalization on the political equilibria. Internationalization enables firms to take advantage of fiscal trade-off thereby reducing the possibility for national government to effectively tax profits. The model shows that the insider coalition is fragilized by the process of internationalization. In fact, this process reduces the resources available for redistribution as well as the margins for the political exchange within the coalition.

The model generates results concerning the macroeconomic equilibrium employment level. We can therefore assess the effects of internationalization on macroeconomic performance. The impact of internationalization depends on the nature of the political system (majoritarian versus coalition government) and on the institutional configuration (positive flexibility versus positive redistribution). In particular, we show that in the case of positive redistribution the internationalization process lowers the intensity of redistribution thus increasing labour demand and employment; in the case of positive flexibility, internationalization reduces job security thus creating real wage pressure and lower employment.

\section{Appendix}

To make sure that the unemployment rate is not so high that the unemployed could be a majority of voters by themselves, we consider that $N_{u}<\frac{1}{2}$. We also exclude the case where workers can by themselves achieve a majority, i.e. $N_{u}>\frac{1-F}{2}$.

1. Flexicurity

$$
\begin{aligned}
& \frac{1-F}{2}<N_{u}^{*}<\frac{1}{2} \\
& N_{u}^{*}=\frac{e \cdot(2+d \cdot(-1+p))+p \cdot\left(-2 \cdot y_{H}+T+W-T \cdot \epsilon\right)}{e+e \cdot p-2 \cdot y_{H} \cdot p}
\end{aligned}
$$

2. Positive flexibility

$$
\frac{1-F}{2}<N_{u}^{*}<\frac{1}{2}
$$

$N_{u}^{*}=\frac{e \cdot(1-p) \cdot\left(e \cdot(-1+p) \cdot\left((-1+d) \cdot\left(y_{H}-y_{L}\right)+2 \cdot T \cdot(1-\epsilon) \cdot(1-\phi)\right)+\left(y_{H}-y_{L}\right) \cdot p \cdot(W-T \cdot(1-\epsilon)) \cdot \phi\right)}{\left(y_{H}-y_{L}\right) \cdot\left(e^{2} \cdot\left(1-p^{2}\right)-2 \cdot e \cdot(1-p) \cdot p \cdot\left(-y_{H}+T \cdot(1-\epsilon) \cdot(1-\phi)\right)+\left(y_{H}-y_{L}\right) \cdot p^{2} \cdot(W-T \cdot(1-\epsilon)) \cdot \phi\right)}$

1. Positive redistribution

$$
\frac{1-F}{2}<N_{u}^{*}<\frac{1}{2}
$$

$N_{u}^{*}=\frac{\left(1+\frac{(1-d) \cdot(1-f) \cdot\left(2 \cdot e \cdot T \cdot(1-\epsilon) \cdot \phi+p \cdot\left(\left(y_{H}-y_{L}\right) \cdot W \cdot(-1+\phi)-T \cdot(1-\epsilon) \cdot\left(y_{L}+y_{H} \cdot(-1+\phi)+2 \cdot e \cdot \phi-y_{L} \cdot \phi\right)\right)\right)}{2 \cdot p \cdot T \cdot(W-T \cdot(1-\epsilon)) \cdot(1-\epsilon)}\right)}{e \cdot(1+p)-\left(y_{H}+d \cdot y_{H}+y_{L}-d \cdot y_{L}\right) \cdot p}$ 


\section{References}

[1] Amable, B. (2003) The diversity of modern capitalism, Oxford University Press.

[2] Amable, B and Gatti, D. (2004) Product market competition, job security and aggregate employment, Oxford Economic Papers, 56(4):667686.

[3] Avi-Yonah, R.S. (2000) Globalization, Tax Competition and the Fiscal Crisis of the Welfare State, 113 Harvard Law Review, May.

[4] Bartelsman, E.J. and Beetsma, R.M.W.J. (2000) Why Pay More? Corporate Tax Avoidance Through Transfer Pricing in OECD Countries, CESifo Working Paper Series No. 324.

[5] Bertola, G. and Boeri, T. (2002) EMU Labour Markets Two Years On: Microeconomic tensions and institutional evolution, pp. 249-280 in M. Buti and A. Sapir (eds.), EMU and Economic Policy in Europe: The Challenge of the Early Years, Edward Elgar, Aldershot.

[6] Bertola, G., Jimeno, J.F., Marimon, R., and Pissarides, C. (2001) EU Welfare Systems and Labor Markets: Diverse in the Past, Integrated in the Future?, pp. 23-122 in G. Bertola, T. Boeri and G. Nicoletti (eds.), Welfare and Employment in a United Europe, MIT Press, Cambridge Mass.

[7] Conseil des impôts [2004] La concurrence fiscale et l'entreprise. Vingtdeuxième rapport au Président de la République. La Documentation Française, Paris.

[8] Crepaz, M.M.L. (1998) Inclusion versus Exclusion: Political Institutions and Welfare Expenditures, Comparative Politics, 31:1, pp. 61-80.

[9] Esping-Andersen, G. (1990) The Three Worlds of Welfare Capitalism, Princeton University Press.

[10] Esping-Andersen, G. (Ed.) (2002) Why we need a New Welfare State, Oxford University Press

[11] Moene, K. O. and Wallerstein, M. (2001) Inequality, Social Insurance, and Redistribution, American Political Science Review, 95:4, 859-74.

[12] Pagano, M. and Volpin, P. (2001) The Political Economy of Corporate Governance, CEPR Discussion Paper no. 2682, forthcoming in The American Economic Review.

[13] Persson, T. and G. Tabellini (2000) Political Economics. Explaining Economic Policy. Cambridge, MA: The MIT Press. 
[14] Persson, T., Roland, G. and Tabellini, G. (2003) How Do Electoral Rules Shape Party Structures, Government Coalitions, and Economic Policies?, NBER Working Paper No. w10176.

[15] Saint-Paul, G. (2001) The political economy of labour market institutions, OUP.

[16] Shapiro, C. and Stiglitz, J. (1984) Equilibrium unemployment as a worker discipline device, The American Economic Review, 74, 433-44.

[17] Swank, D. and Steinmo, S. (2002) The New Political Economy of Taxation in Advanced Capitalist Democracies, American Journal of Political Science, 46:3, 642-55.

[18] Visser, Jelle et A. Hemerijck (1999) A Dutch Miracle. Job Growth, Welfare Reform and Corporatism in the Netherlands, Amsterdam University Press. 